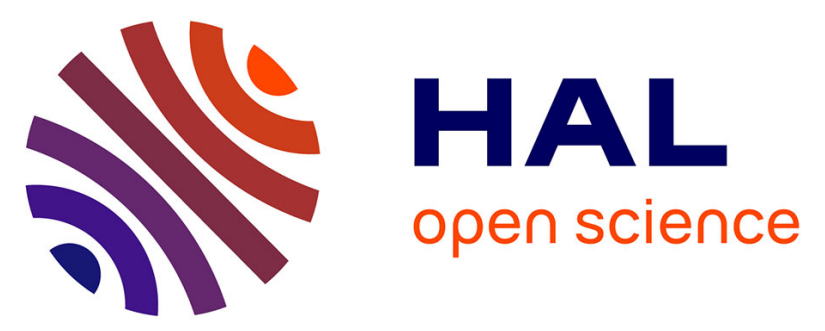

\title{
Single-Center Experience Using the 3MAX Reperfusion Catheter for the Treatment of Acute Ischemic Stroke with Distal Arterial Occlusions
}

Kévin Premat, Bruno Bartolini, Flore Baronnet-Chauvet, Eimad Shotar, Vincent Degos, Paul Muresan, Federico Di Maria, Joseph Gabrieli, Charlotte Rosso, Silvia Pistocchi, et al.

\section{To cite this version:}

Kévin Premat, Bruno Bartolini, Flore Baronnet-Chauvet, Eimad Shotar, Vincent Degos, et al.. SingleCenter Experience Using the 3MAX Reperfusion Catheter for the Treatment of Acute Ischemic Stroke with Distal Arterial Occlusions. Clinical Neuroradiology, 2018, 28 (4), pp.553-562. 10.1007/s00062017-0594-8 . hal-01944138

\section{HAL Id: hal-01944138 https://hal.sorbonne-universite.fr/hal-01944138}

Submitted on 14 Jan 2019

HAL is a multi-disciplinary open access archive for the deposit and dissemination of scientific research documents, whether they are published or not. The documents may come from teaching and research institutions in France or abroad, or from public or private research centers.
L'archive ouverte pluridisciplinaire $\mathbf{H A L}$, est destinée au dépôt et à la diffusion de documents scientifiques de niveau recherche, publiés ou non, émanant des établissements d'enseignement et de recherche français ou étrangers, des laboratoires publics ou privés. 
2 Catheter for the Treatment of Acute Ischemic Stroke with

\section{Distal Arterial Occlusions}

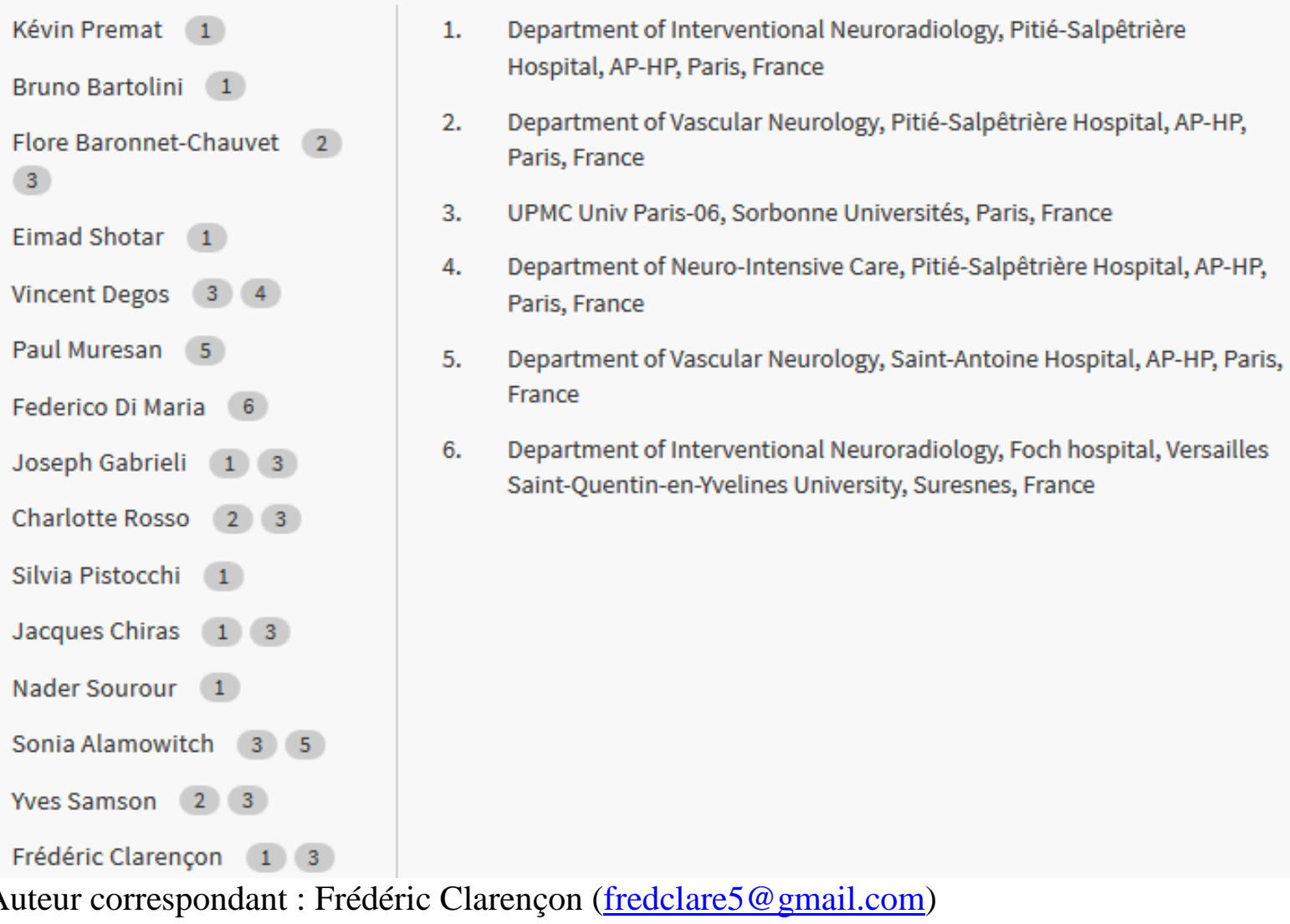


Acronyms and Abbreviations:

7 AcomA: Anterior Communicating Artery

8 ACA: Anterior Cerebral Artery

9 ADAPT: A Direct Aspiration first-Pass Thrombectomy

10 AIS: Acute Ischemic Stroke

11 DSA: Digital Subtraction Angiography

12 ENT: Embolus to New Territory

13 IVT: Intravenous Thrombolysis

14 LVO: Large Vessel Occlusion

15 MCA: Middle Cerebral Artery

16 mRS: modified Rankin Scale

17 MRI: Magnetic Resonance Imaging

18 MT: Mechanical Thrombectomy

19 NIHSS: National Institute of Health Stroke Score

20 PCA: Posterior Cerebral Artery

21 r-TPA: recombinant tissue plasminogen activator

22 SCA: Superior Cerebellar Artery

23 SICH: Symptomatic IntraCranial Haemorrhage

24 TICI: Thrombolysis In Cerebral Infarction 


\section{INTRODUCTION}

26 The management of acute ischemic stroke (AIS) in patients with large vessel occlusion (LVO) has been

27

28

29

30

31

32

33

34 drastically modified by the positive results of 5 randomized clinical trials testing mechanical thrombectomy (MT) compared to the standard guideline-based therapy.[1-5] These studies led the American Stroke Association and American Heart Association to edict guidelines in June 2015 recommending that patients with AIS caused by LVO should be referred to MT by preferentially using stent retriever devices.[6]. The Direct Aspiration first-Pass Thrombectomy technique (ADAPT) using supple reperfusion catheters has shown convincing results in terms of reperfusion rates and procedure time reduction for LVO.[7,8] However, only scant data are available for smaller catheters like the 3MAX in distal occlusions.[9,10]

The primary endpoint of the study was the successful (i.e. Thrombolysis In Cerebral Infarction [TICI] score $2 \mathrm{~b} / 3$ ) reperfusion rate using ADAPT with the 3MAX. Secondary evaluation criteria were 3MAX-related complications and good clinical outcome (defined as $\mathrm{mRS} \leq 2$ ) at 3 months. 
To evaluate the navigability, the safety and the ability to successfully reperfuse distal occlusions, we conducted a retrospective analysis of all consecutive patients with AIS for whom the 3MAX was used at least once in distal MT. Distal occlusions were defined as follows: ACA occlusions (from A2), MCA occlusions (from M2), PCA occlusions (from P1), Cerebellar arteries' occlusions. The M2 (a.k.a insular) segment was defined as the part of the MCA from the genu to the circular insular sulcus.

From August 2015 to December 2016, 32 consecutive patients (16 females [50\%] and 16 males [50\%]; mean age $=67.4 \pm 18.7 \mathrm{y}$, [range: 22-91]) for 38 distal occlusions underwent MT using the 3MAX. Five patients were treated for multiple occlusions. Four out of the 32 patients included in this study (12.5\%) underwent MT subsequently to iatrogenic thromboembolic events, 3 among them occurred during neurointerventional procedures: the first patient had left acute M2 occlusion during the endovascular treatment of a vasospasm at day 10 after embolization of a ruptured anterior communicating artery (AcomA) aneurysm, the second patient had acute right $\mathrm{M} 3$ occlusion during the coiling of a ruptured AcomA aneurysm and the third patient presented multiple M3 occlusions in the aftermath of a periprocedural rupture of an AcomA aneurysm. The last patient had acute left M2 occlusion during a diagnostic coronarography. Of the 32 patients, 5 (15.6\%) had tandem occlusions (two vertebrobasilar tandem occlusions and three internal carotid artery/middle cerebral artery tandem occlusions). Device:

The Penumbra 3MAX is the smallest reperfusion catheter designed to perform the most distal thrombectomies. The distal outer and inner diameters are respectively $3.8 \mathrm{~F}(1.27 \mathrm{~mm}, 0.050$ inches $)$ and $2.7 \mathrm{~F}(0.89 \mathrm{~mm}, 0.035$ inches) with a proximal outer diameter of $4.7 \mathrm{~F}(1.57 \mathrm{~mm}, 0.062$ inches) and a $153 \mathrm{~cm}$ working length. It is designed to be mounted over a compatible 5-6F intermediate catheter to provide better support to the system. electric aspiration pump. 
Preoperative evaluation included a medical examination with neurological assessment performed by a stroke neurologist using the National Institute of Health Stroke Score (NIHSS) swiftly followed by a brain Magnetic Resonance Imaging (MRI) to confirm the diagnosis, evaluate the ischemic lesion burden, assess the arterial occlusion and plan the procedure. According to our local guidelines, MRI is preferred to CT scan in patients with suspicion of AIS eligible for intravenous thrombolysis (IVT) and/or MT. Eighteen out of the 32 (56.3\%) patients had IVT (r-TPA) before the endovascular procedure in a bridging fashion. All patients underwent this preoperative standardized management except for those whose thromboembolic event was depicted during neurointerventional procedures. In these latter cases the NIHSS could not be evaluated.

MT Procedure:

All MT were performed under general anaesthesia $(n=19[59.4 \%])$ or conscious sedation $(n=13[40.6 \%])$. According to the ADAPT technique, an intermediate aspiration catheter (5MAX/ACE/ACE64 [Penumbra] or SOFIA/SOFIA PLUS [MicroVention Inc. Tustin CA, USA]) was mounted over the 3MAX and a 0.014" microguide wire. The 3MAX was then positioned just upstream from the clot. The microguide wire was removed and the 3MAX was connected to the aspiration system to engage the clot. The 3MAX was then pulled back in the intermediate catheter under constant aspiration, and a control DSA was performed after each aspiration (Figure 1). A median of $2 \pm 1.1$ (IQR: 1-5) aspiration attempts was performed. If recanalization could not be achieved with ADAPT, the so-called "Solumbra" technique was attempted at the operator's discretion by deploying a stent retriever (Solitaire Flow Restoration device [ev3-Covidien, Irvine, CA, USA] and/or pREset [Phenox GmbH, Bochum, Germany]) through a Velocity 2.6F delivery microcatheter (Penumbra).

\section{Evaluation criteria:}

In each case, the feasibility of using the $3 \mathrm{MAX}$ (i.e.: ability to reach the occlusion site in the target vessel) was assessed. Efficacy of thromboaspiration through the 3MAX was evaluated using the TICI score.[11] Intracerebral hemorrhages were graded according to the SITS-MOST classification.[12] Major procedure-related 
complications (procedure-related death, vessel perforation, emboli in a new territory [ENT]) including 3MAXrelated complications as well as minor complications (vasospasm after thrombo-aspiration on the target vessel, minor puncture site complication) were also recorded. For each patient, delays from symptoms' onset to arterial puncture, symptoms' onset to successful reperfusion, reperfusion time (i.e. time from arterial puncture to recanalization) and procedure lasting were also evaluated.

\section{Imaging and clinical follow-up:}

All patients had post-MT dual-energy CT scan to depict early hemorrhagic complications and differentiate them from post-procedural contrast media extravasation [13]. All living patients had a control brain MRI within the $48 \mathrm{~h}$ after MT to evaluate the extent of the ischemic lesions, depict potential complications and rule out reocclusion of the target vessel. Patients under general anaesthesia were extubated immediately after procedure if their clinical status allowed it. Neurological impairment was assessed using the NIHSS at admission, at day 1 and at discharge after exclusion of the deceased patients. Disability was evaluated with the modified Rankin Scale (mRS) performed at discharge and at 3 months, when available. A good functional outcome was defined as a $\mathrm{mRS}$ score $\leq 2$. All additional radiological exams, biology and medical consultations were also reviewed.

\section{Statistical analysis:}

Data analysis was performed using EPI Info 7.1.5.2 software (Centers for Disease Control and Prevention [CDC] Atlanta, Georgia, USA). Results are presented as means \pm standard deviations and ranges or medians with their interquartile range (IQR). Comparison of means was performed using a Student-t test or Wilcoxon test, depending on the data distribution. Results were considered statistically significant when $\mathrm{P}$-values $<0.05$.

\section{Ethical Statement:}

Neither approval of the institutional review board nor patient informed consent are required by the ethics committee of our institution for retrospective analyses of patients' records and imaging data. 


\section{RESULTS}

Patients' demographics and results are summarized in Table 1.

120

121

122

123

124

125

126

127

128

129

130

131

132

\section{Overall results}

In one case (2.6\%) of a $1.3 \mathrm{~mm}$ superior cerebellar artery (SCA) occlusion, the 3MAX could not be navigated. ADAPT alone with the 3MAX allowed successful (TICI 2b/3) reperfusion in 59.5\% of the cases. In 10 cases (26.3\%), the complementary "Solumbra" technique was used which allowed successful recanalization in 7 cases, thus achieving an overall reperfusion rate of $76.3 \%$.

Median NIHSS score improved from 14 (IQR: 9-19) at admission to 9 (IQR: 5-18) at 24 hours to 6 (IQR:3-12) at discharge. mRS score was available for 23 patients (71.9\%) at discharge and for 22 patients at 3 months (68.8\%). A good functional outcome (mRS $\leq 2$ ) was obtained in $19 \%$ of the patients at discharge and $45.5 \%$ at 3 months.

Average delay between symptoms' onset and arterial puncture was $235.5( \pm 113.8)$ minutes, average reperfusion time was $67.7( \pm 33.4)$ minutes and procedures lasted a mean of $85.5( \pm 38.0)$ minutes.

Five patients (15.6\%) died during the follow-up: one at day 17 and one at day 67 from unrelated causes, two from remote (contralateral) parenchymal haemorrhages ( $\mathrm{PHrp} 2$ ) subsequently to the therapeutical management (MT and IVT for both patients), and one from a multi-visceral failure. Six (18.8\%) major procedure-related complications occurred including three (9.4\%) 3MAX-related (2 ENTs and one vascular perforation). It is noteworthy that the ENTs were easily removed using ADAPT, and were not responsible for any clinical sequelae. The other major procedure-related complications were: two vascular perforations (one microguide wire-induced lenticulostriate perforation without any clinical consequences and one after stent retrieval) and one ipsilateral central retinal artery occlusion. In six patients, intracerebral haemorrhages were depicted: $3(9.4 \%)$ SICH (2 PHrp2 and 1 PH2), 2 HI1, 1 PH1. Three of them also had asymptomatic subarachnoid haemorrhages. Significant spasm (defined as $>50 \%$ of the target vessel's lumen) was seen in 7/38 (18.4\%) arteries after ADAPT with the $3 \mathrm{MAX}$. Three of them spontaneously regressed before the end of the procedure.

\section{Anterior versus posterior circulation occlusions}


144 Seven out of the 37 occlusions (18.9\%) affected the posterior circulation. The median baseline NIHSS was lower 145 in posterior distal occlusions (7 [IQR: 5-28] vs 15 [IQR: 12-24]; p=0.47). The rate of successful reperfusion was 146 non significantly higher in the posterior occlusion group $(85.7 \%$ vs $53.3 \%$; $>0.5)$ and also after rescue stent retriever thrombectomy $(100 \%$ vs $75 \%$; $>0.5)$. Posterior occlusions were associated with a significantly better

148 clinical outcome at 3 months (100\% vs $44.4 \%$; $=0.029)$ even though no statistical difference in NIHSS at discharge was found (5 [IQR: 4-11] vs 3 [IQR: 0-4] in the posterior group; $\mathrm{p}>0.5$ ).

MT for iatrogenic thromboembolic events

152 Four iatrogenic thromboembolic events were included in the analysis. Successful reperfusion by 3MAX ADAPT 153 alone was obtained in 3 of the 4 cases $(80 \%)$ and for the last patient, additional stent retriever passages did not achieve successful reperfusion. Good clinical outcome at 3 months was achieved in $50 \%$ of cases. No embolic or hemorrhagic complication was recorded. reperfusion was achieved in $56.3 \%$ of cases with the $3 \mathrm{MAX}$ alone and in $75 \%$ of cases after complementary stent retriever thrombectomy. A good functional outcome could be obtained in $44 \%$ of cases. The results were not significantly different from the main analysis. 
161

162

163

In the presented series, $59.5 \%$ of patients had successful TICI $2 \mathrm{~b} / 3$ reperfusion after ADAPT alone with the $3 \mathrm{MAX}$ and complementary stent retrieving techniques allowed to achieve an overall recanalization rate of $76.3 \%$ but three (9.4\%) 3MAX-related major complications were recorded. Hence, a good functional outcome was obtained in only $45.5 \%$ of patients at 3 months.

ADAPT has gained acceptance as a safe and effective alternative to stent retrievers in LVO.[14,15] The THERAPY trial [16] supposed to compare thromboaspiration to IVT alone was halted due to emergent proof of the added value of MT over IVT alone, and did not achieve its primary endpoint. Thus there is a lack of solid evidence for ADAPT even though complementary data suggested that ADAPT is not inferior to primary stent retriever thrombectomy.[17]

\section{Distal intracranial occlusions}

For distal occlusions of the MCA, Saqqur et al.[18] reported a $44.2 \%$ rate of complete reperfusion after IVT alone. Dorn et al.[19] compared stentriever-based MT in M2 vs M1 occlusions and reported a higher reperfusion rate $(93.3 \%$ versus $76.0 \% ; \mathrm{p}=0.186)$ with fewer periprocedural complications (None vs 3 ) in M2 occlusions.

Literature provides only retrospective series focused on distal occlusions (Table 2) mainly treated with stent retrievers and displays heterogeneous reperfusion rates (from 70 to $100 \%$ ) but low complication rates[9,10,1924]. Navia et al.[9] provided a 6 cases series of distal occlusions treated with ADAPT and found a 100\% TICI $2 \mathrm{~b} / 3$ reperfusion rate with a $83 \%$ rate of good clinical outcome, no complication and no need to use stent retrievers. Due to the very low number of patients included, direct comparison is delicate. Also in this publication, the strokes' etiologies were not precised and maybe clots from different nature or different underlying condition may explain discrepancies with our results.

The choice between ADAPT and stent retriever thrombectomy as the frontline technique is not yet elucidated and the answer is probably not univocal. This study shows that the 3MAX can navigate efficiently in most situations and reach very distal occlusions, up to A3, M3 or P3 segments (Figure 2). Arguably, as a faster, safer and more cost-effective method[8], ADAPT with the 3MAX is acceptable as the frontline technique for distal occlusions. Kim et al.[23] compared forced arterial suction ( $\mathrm{n}=25$ patients) to stent retriever thrombectomy 
$(\mathrm{n}=16)$ as the frontline technique in M2 occlusions and found a tendency toward a better reperfusion rate (64\% vs $81.2 \% ; \mathrm{p}=0.305$ ) with stent retrievers. No statistically significant differences in complication and good functional outcome rates were depicted. Authors also identified that an M2 occlusion located immediately after a severe angulation was associated with an increased rate of failure with ADAPT. In our series a perforation occurred in this exact location, supporting the fact that adequate assessment of the target vessel is crucial when choosing between ADAPT and stent retriever. Vargas et al. [10] proposed a series of 35 patients treated with ADAPT for distal occlusion which was very similar to our study. They reported a TICI $2 \mathrm{~b} / 3$ rate of $77.1 \%$ after ADAPT alone with a conversion rate of $20 \%$ to achieve an overall reperfusion rate of $97.1 \%$ and reached good clinical outcome in $59.4 \%$ of patients at 3 months. Due to the limited number of patients in both our studies, direct comparison is hazardous however additional devices permitted to rescue a substantial amount of remaining occlusions. The $3 \mathrm{MAX}$ seemed more efficient in very distal occlusions due to the increasement of aspiration force as the vessel's diameter gets closer to the 3MAX'. As reported in subgroup analysis, the 3MAX might be helpful in iatrogenic distal occlusions or in ENT to achieve successful reperfusion with a good level a safety, which remains essential in this context. Very acute clots may be more able to pass into small diameter catheters, making them easier to remove by aspiration. Hence, avoiding to deploy a stent that may seem more invasive in small vessels. Nevertheless, the self-reported reperfusion results showed that ADAPT alone with the 3MAX was able to recanalize most of distal occlusions even in the posterior circulation but was insufficient as the sole reperfusion device. Stent retrievers were still needed and rescued 7 of the 15 (46.7\%) remaining occlusions. Moreover, in one case of a proximal SCA (Fig 1.) occlusion, the target SCA could not be catheterized due to vessel's angulation and small diameter. In the latter case, a Velocity microcatheter could reach the target occlusion, allowing successful reperfusion of the artery by deploying a Solitaire. For very challenging intracranial catheterization, stent retrievers might be preferred, not for their superiority to reperfuse but simply because the tractability of the delivery microcatheter is more suitable.

\section{Complications}

MT for distal occlusions is controversial as it is known to be technically challenging and associated with a higher complication rate which is confirmed by the presented results. We experienced a perprocedural 3MAX-related rupture at the M1-M2 angulation point point which was managed by glue occlusion. Ultimately, the patient presented a multivisceral failure at day $9(\mathrm{mRS} 6)$. Contrast media extravasation and pseudoaneurysm formation 
after aspiration thrombectomy have already been described with distal aspiration catheters such as the 4MAX [26]. One must always consider that these catheters can be harmful even on large intracranial arteries especially at junction points or in tortuous segments. In comparison, Vargas et al.'s [10] series comprised 80\% isolated M2 occlusions, one M3 and one A3 occlusion; they reported two major procedure-related complications. In our series, we aimed to reperfuse even very distal occlusions up to A3 (one case), M3 (six cases) and P3 (two cases) which inevitably exposes to a greater risk of complications.

ENT may be encountered with all types of MT devices. However, in the literature, the ENT rate seems lower with aspiration devices (from $0 \%$ to $6 \%$ ) [27,28] than with the stentrievers (from 0\% to 13.3\%).[29,30] ENTs were observed in two cases in our series, which could be easily recanalized with the 3MAX without any clinical consequence.

Even though average NIHSS score was similar to other series, a low rate of good functional outcome at 3 months was obtained. This can be explained by a higher rate of major complications and the inclusion of patients in poor general condition (ruptured intracranial aneurysms, advanced cardiovascular diseases or recovered cardiac arrest before MT).

\section{Procedure times}

Average reperfusion time was $67.7( \pm 33.4)$ minutes in this series and was rather long in comparison to the study of Vargas et al.[10] who obtained a mean time to recanalization of 35.5 ( \pm 26.4 minutes) with distal ADAPT. It is a direct consequence of an inferior reperfusion rate after ADAPT alone and a superior rate of perprocedural complications. Moreover five patients had multiple occlusions and five had tandem occlusions which considerably increased the time of procedures.

\section{Limitations}

The value of this study is limited by the retrospective and monocentric fashion of data collection and analysis as well as the small volume of patients included. We also purposely included patients with iatrogenic thromboembolic events to display a more representative population who may benefit from distal recanalization. However, the nature of the clots encountered in thromboembolic events occurring during embolization is 
243 probably different from the one observed in patients with non-iatrogenic acute ischemic stroke. The lack of 244 control group and the fact that $\mathrm{mRS}$ at 3 months was available for only $62.5 \%$ of the patients does not allow an 245 optimal assessment of clinical outcome. Furthermore, mRS is probably an inaccurate tool to evaluate the 246 outcome of patients with distal occlusions, especially in the ACA's and vertebrobasilar territories where the 247 clinical consequences (behavioral disorders, anopsia, dyspraxia...) are not adequately assessed by this scale. 


\section{CONCLUSION}

251 The 3MAX reperfusion catheter is a well-navigable catheter, making it acceptable as a frontline technique in

252 distal MT, especially in case of periprocedural thromboembolic event but in general, the reperfusion rate appears

253 insufficient with ADAPT alone thus preventing operators from relying on it as the sole revascularization device.

254 One must also be aware of the risk of vascular injury, especially in tortuous and angulated segments.

255 Randomized trials are needed to efficiently compare ADAPT to stent retrievers.

256 


\section{REFERENCES}

1. Berkhemer OA, Fransen PSS, Beumer D, van den Berg LA, Lingsma HF, Yoo AJ, et al. A Randomized Trial of Intraarterial Treatment for Acute Ischemic Stroke. N. Engl. J. Med. 2015;372:11-20.

2. Saver JL, Goyal M, Bonafe A, Diener H-C, Levy EI, Pereira VM, et al. Stent-retriever thrombectomy after intravenous t-PA vs. t-PA alone in stroke. N. Engl. J. Med. 2015;372:2285-95.

3. Goyal M, Demchuk AM, Menon BK, Eesa M, Rempel JL, Thornton J, et al. Randomized assessment of rapid endovascular treatment of ischemic stroke. N. Engl. J. Med. 2015;372:1019-30.

4. Jovin TG, Chamorro A, Cobo E, de Miquel MA, Molina CA, Rovira A, et al. Thrombectomy within 8 hours after symptom onset in ischemic stroke. N. Engl. J. Med. 2015;372:2296-306. therapy for ischemic stroke with perfusion-imaging selection. N. Engl. J. Med. 2015;372:1009-18.

6. Powers WJ, Derdeyn CP, Biller J, Coffey CS, Hoh BL, Jauch EC, et al. 2015 American Heart Association/American Stroke Association Focused Update of the 2013 Guidelines for the Early Management of Patients With Acute Ischemic Stroke Regarding Endovascular Treatment A Guideline for Healthcare Professionals From the American Heart Association/American Stroke Association. Stroke. 2015;46:3020-35.

7. Vargas J, Spiotta A, Fargen K, Turner R, Chaudry I, Turk A. Long term experience using the ADAPT technique for the treatment of acute ischemic stroke. J. Neurointerventional Surg. 2016;

8. Turk AS, Campbell JM, Spiotta A, Vargas J, Turner RD, Chaudry MI, et al. An investigation of the cost and benefit of mechanical thrombectomy for endovascular treatment of acute ischemic stroke. J. NeuroInterventional Surg. 2014;6:77-80.

9. Navia P, Larrea J-A, Pardo E, Arce A, Martínez-Zabaleta M, Díez-González N, et al. Initial experience using the $3 \mathrm{MAX}$ cerebral reperfusion catheter in the endovascular treatment of acute ischemic stroke of distal arteries. J. Neurointerventional Surg. 2015;

10. Vargas J, Spiotta AM, Fargen K, Turner RD, Chaudry I, Turk A. Experience with A Direct Aspiration First Pass Technique (ADAPT) for Thrombectomy in Distal Cerebral Artery Occlusions Causing Acute Ischemic Stroke. World Neurosurg. 2017;99:31-6.

11. Zaidat OO, Yoo AJ, Khatri P, Tomsick TA, von Kummer R, Saver JL, et al. Recommendations on angiographic revascularization grading standards for acute ischemic stroke: a consensus statement. Stroke. 2013;44:2650-63.

12. Wahlgren N, Ahmed N, Dávalos A, Ford GA, Grond M, Hacke W, et al. Thrombolysis with alteplase for acute ischaemic stroke in the Safe Implementation of Thrombolysis in Stroke-Monitoring Study (SITS-MOST): an observational study. Lancet Lond. Engl. 2007;369:275-82.

13. Tijssen MPM, Hofman P a. M, Stadler A a. R, van Zwam W, de Graaf R, van Oostenbrugge RJ, et al. The role of dual energy CT in differentiating between brain haemorrhage and contrast medium after mechanical revascularisation in acute ischaemic stroke. Eur. Radiol. 2014;24:834-40.

14. Hussain SI, Zaidat OO, Fitzsimmons B-FM. The Penumbra system for mechanical thrombectomy in endovascular acute ischemic stroke therapy. Neurology. 2012;79:S135-141. 
15. Romano DG, Cioni S, Vinci SL, Pero G, Comelli C, Comai A, et al. Thromboaspiration technique as first approach for endovascular treatment of acute ischemic stroke: initial experience at nine Italian stroke centers. J. Neurointerventional Surg. 2017;9:6-10.

16. Mocco J, Zaidat OO, von Kummer R, Yoo AJ, Gupta R, Lopes D, et al. Aspiration Thrombectomy After Intravenous Alteplase Versus Intravenous Alteplase Alone. Stroke. 2016;47:2331-8.

17. Stapleton CJ, Torok CM, Patel AB. 110 Noninferiority of a Direct Aspiration First-Pass Technique vs Stent Retriever Thrombectomy in Emergent Large-Vessel Intracranial Occlusions. Neurosurgery. 2016;63 Suppl 1:146-7.

18. Saqqur M, Uchino K, Demchuk AM, Molina CA, Garami Z, Calleja S, et al. Site of arterial occlusion identified by transcranial Doppler predicts the response to intravenous thrombolysis for stroke. Stroke J. Cereb. Circ. 2007;38:948-54.

19. Dorn F, Lockau H, Stetefeld H, Kabbasch C, Kraus B, Dohmen C, et al. Mechanical Thrombectomy of M2-Occlusion. J. Stroke Cerebrovasc. Dis. Off. J. Natl. Stroke Assoc. 2015;24:1465-70.

20. Pfaff J, Herweh C, Pham M, Schieber S, Ringleb PA, Bendszus M, et al. Mechanical Thrombectomy of Distal Occlusions in the Anterior Cerebral Artery: Recanalization Rates, Periprocedural Complications, and Clinical Outcome. AJNR Am. J. Neuroradiol. 2016;37:673-8.

21. Kurre W, Aguilar-Pérez M, Martinez-Moreno R, Schmid E, Bäzner H, Henkes H. Stent Retriever Thrombectomy of Small Caliber Intracranial Vessels Using pREset LITE: Safety and Efficacy. Clin. Neuroradiol. 2016;

22. Coutinho JM, Liebeskind DS, Slater L-A, Nogueira RG, Baxter BW, Levy EI, et al. Mechanical Thrombectomy for Isolated M2 Occlusions: A Post Hoc Analysis of the STAR, SWIFT, and SWIFT PRIME Studies. AJNR Am. J. Neuroradiol. 2016;37:667-72.

23. Kim Y-W, Son S, Kang D-H, Hwang Y-H, Kim Y-S. Endovascular thrombectomy for M2 occlusions: comparison between forced arterial suction thrombectomy and stent retriever thrombectomy. J. Neurointerventional Surg. 2016;

24. Park JS, Kwak HS. Manual Aspiration Thrombectomy Using Penumbra Catheter in Patients with Acute M2 Occlusion : A Single-Center Analysis. J. Korean Neurosurg. Soc. 2016;59:352-6.

26. Jeong E-O, Kwon H-J, Choi S-W, Koh H-S. Pseudoaneurysm Formation after Repetitive Suction Thrombectomy Using a Penumbra Suction Catheter. J. Cerebrovasc. Endovasc. Neurosurg. 2016;18:296-301.

27. Investigators TPPST. The Penumbra Pivotal Stroke Trial Safety and Effectiveness of a New Generation of Mechanical Devices for Clot Removal in Intracranial Large Vessel Occlusive Disease. Stroke. 2009;40:2761-8.

28. Kowoll A, Weber A, Mpotsaris A, Behme D, Weber W. Direct aspiration first pass technique for the treatment of acute ischemic stroke: initial experience at a European stroke center. J. Neurointerventional Surg. 2016;8:230-4.

29. Stampfl S, Kabbasch C, Müller M, Mpotsaris A, Brockmann M, Liebig T, et al. Initial experience with a new distal intermediate and aspiration catheter in the treatment of acute ischemic stroke: clinical safety and efficacy. J. Neurointerventional Surg. 2015; 
337 30. Gascou G, Lobotesis K, Machi P, Maldonado I, Vendrell JF, Riquelme C, et al. Stent Retrievers in 338 Acute Ischemic Stroke: Complications and Failures during the Perioperative Period. Am. J.

339 Neuroradiol. 2014;35:734-40.

340

341 

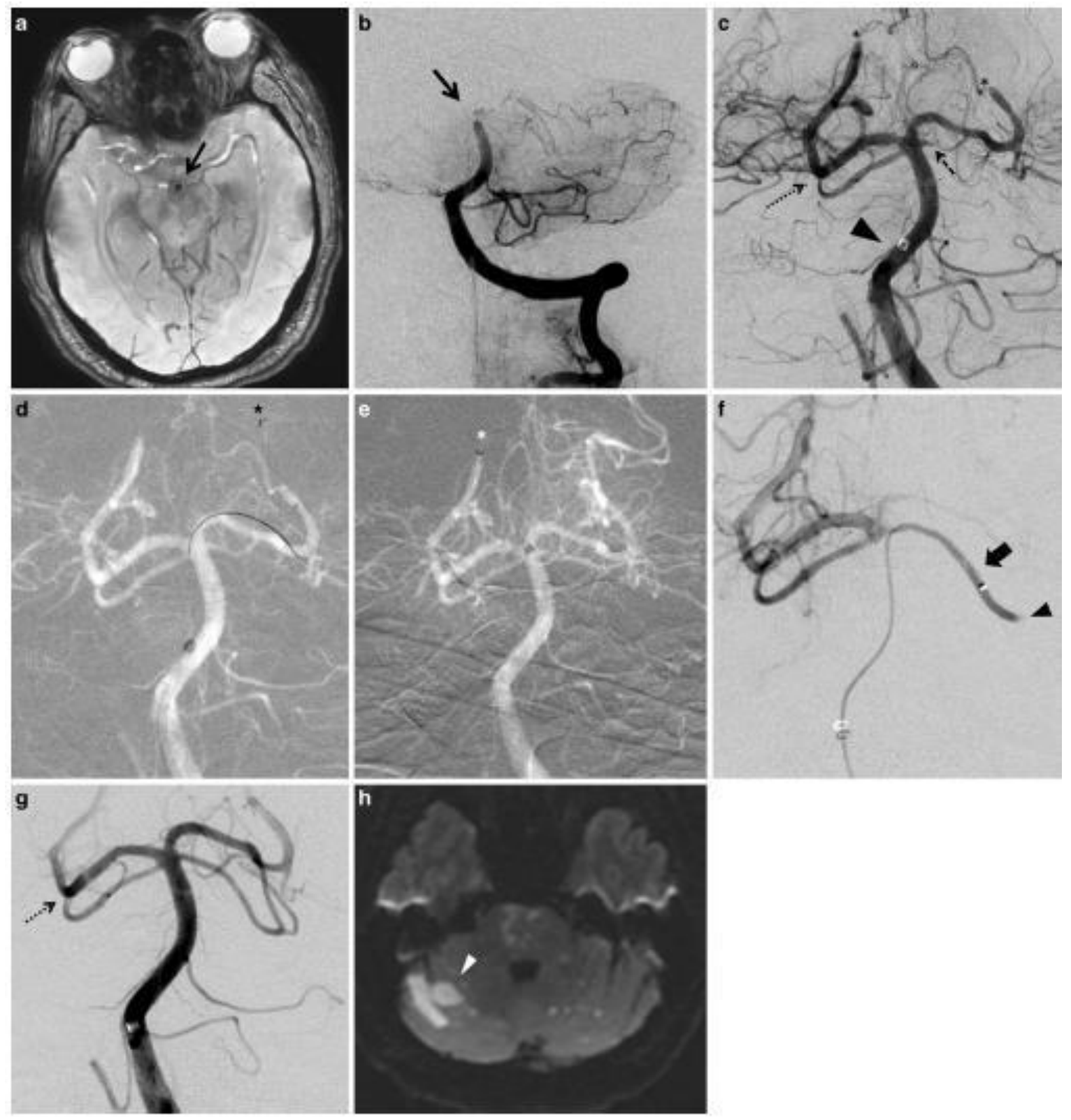

Sixty-seven-year-old male patient with sudden onset of coma (NIHSS 28). A. Axial susceptibility-weighted MR images showing signal void inside the distal basilar artery assessing the presence of the clot which was confirmed by the MR angiography and during per-procedural selective left vertebral artery DSA (B. Black arrow) C. DSA through the ACE64 (Black arrow head): clot fragmentation caused by the initial road map injection for catheter navigation is demonstrated: bilateral PCA occlusions (P3, black asterisks) and bilateral SCA occlusions (First segment on the left side and second segment on the right side [Dotted arrows]) are seen. 
D. Road map in AP projection. After two failed thromboaspiration attempts with the 3MAX, recanalization of

352

353

354

355

356

357

358

359

360

361

362
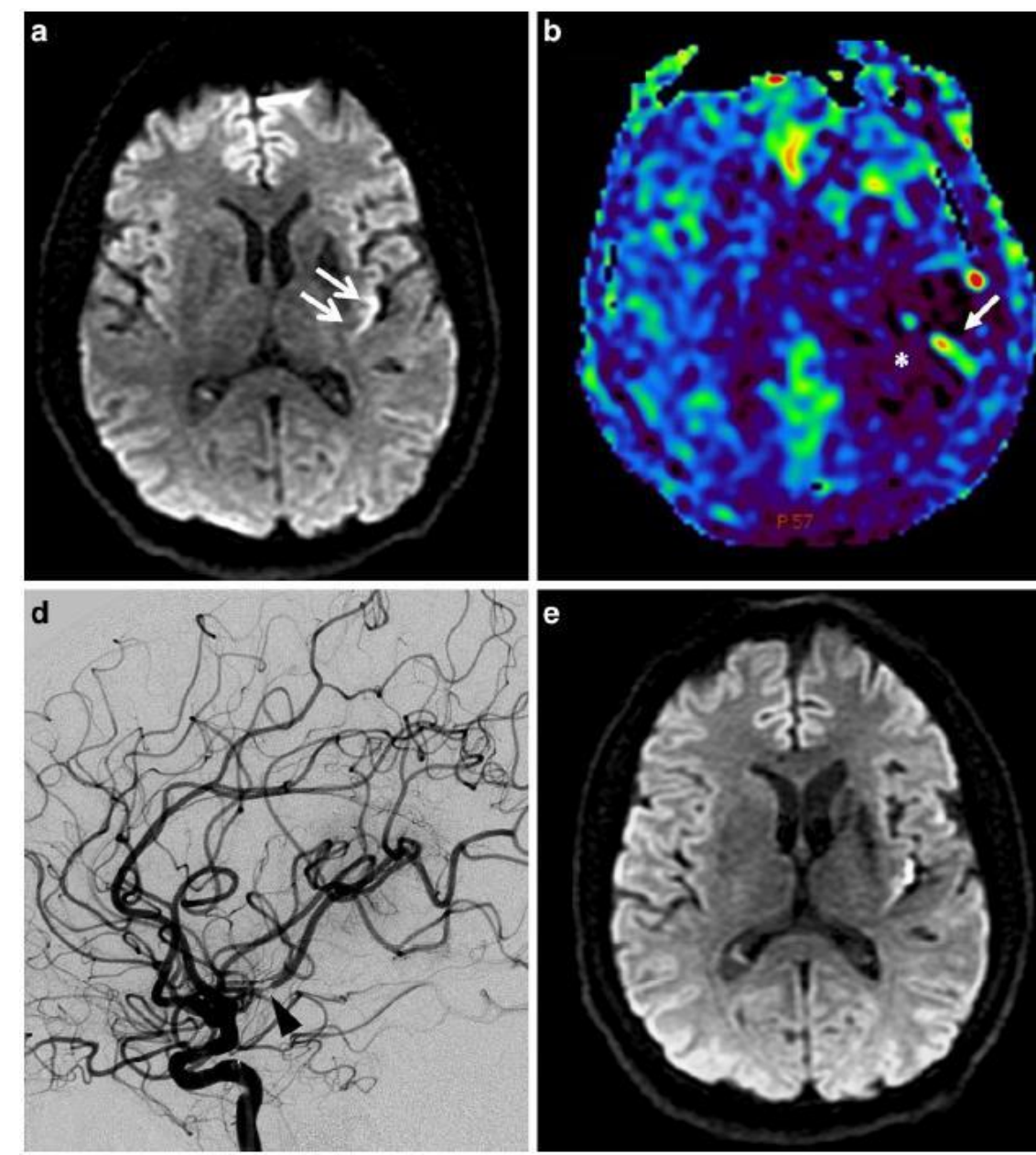
arrowhead).

Figure 2.

(1)

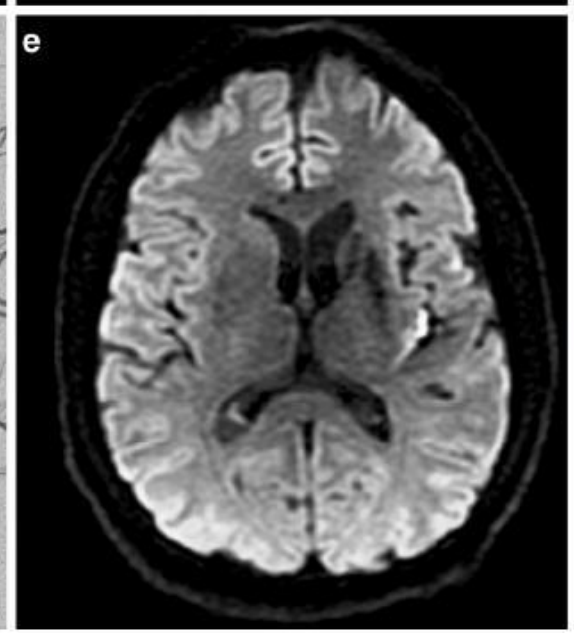
the left PCA was obtained with a stent retriever (4/20 mm Solitaire FR; black star) (TICI 3 recanalization). E. Road map in AP projection: direct thromboaspiration through the 3MAX is successfully performed on the right PCA occlusion (white asterisk). F. Selective DSA through a Velocity 2.6F delivery microcatheter (Large arrow) (Penumbra) placed into the left SCA after a failed 3MAX navigation attempt, showing occlusion of the left SCA (black arrowhead). TICI 3 was obtained after the second stent retrieving attempt with a Solitaire FR. G. Control DSA in AP projection: TICI 3 recanalization of both PCAs and left SCA. Partial spontaneous recanalization of the right SCA during the procedure is also seen (arrow). H. Axial diffusion weighted images at day 1 after MT: multiple punctuate infarcts as well as an infarct in the right SCA territory are seen (lateral branches; white
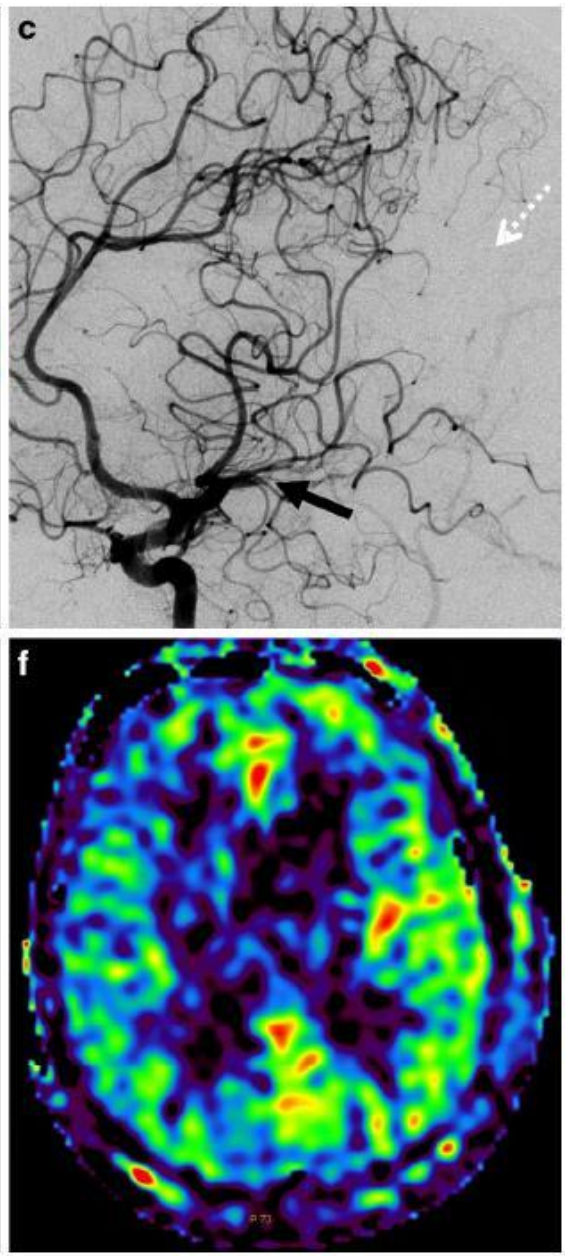
Fifty-year-old patient with acute onset aphasia and partial motor deficit (NIHSS = 6) due to a left M2 occlusion who underwent IVT+MT at 3 hours from symptoms' onset. A. Diffusion Weighted Imaging (DWI); axial slice showing small insular and opercular acute ischemic stroke (white arrows). B. Arterial Spin Labelling (ASL) perfusion MRI sequence displaying a large hypoperfusion (white asterisk) in the occluded territory assessing the DWI-Perfusion mismatch. Note the linear hyperperfusion corresponding to a transit arterial artefact, related to slowdown in a cortical branch (white arrow). C: Left internal carotid artery selective DSA in left anterior oblique (LAO) projection: inferior division M2 branch occlusion (black arrow) with arterial defect in the corresponding territory (white dotted arrow) are seen. D: Control DSA after two thromboaspiration attempts: TICI 2b

372 recanalization after 26 minutes of recanalization time. Note the significant spasm at the occlusion's level

373 (arrowhead). E: Control MRI 24h after MT, DWI; axial slice: no extension of ischemia is seen. F. ASL

374 perfusion sequence at day 1 showing complete reperfusion of the posterior MCA territory defect. Note the faint hyperperfusion of the previously hypoperfused territory, also known as "luxury perfusion". 
Table 1. Population characteristics, technical parameters and results

\begin{tabular}{|c|c|}
\hline Characteristics & Value \\
\hline Sex & \\
\hline -Male & $16(50 \%)$ \\
\hline Mean age: years $( \pm$ S.D) & $67.4( \pm 18.7)$ \\
\hline Strokes' etiologies & \\
\hline -Atherosclerosis & $6(18.8 \%)$ \\
\hline -Cardioembolic & $17(53.1 \%)$ \\
\hline -Embolic, iatrogenic & $4(12.5 \%)$ \\
\hline -Unknown & $5(15.6 \%)$ \\
\hline Median NIHSS score (IQR) & \\
\hline -At admission & $14(9-19)$ \\
\hline -At 24 hours & $9(5-18)$ \\
\hline -At day 7 & $6(3-12)$ \\
\hline Occlusion's location & \\
\hline$-\mathrm{M} 2:$ & $23(60.5 \%)$ \\
\hline -M3: & $6(15.8 \%)$ \\
\hline$-\mathrm{P} 1:$ & $3(7.9 \%)$ \\
\hline$-\mathrm{P} 2$ : & $2(5.3 \%)$ \\
\hline -P3: & $2(5.3 \%)$ \\
\hline$-A 3:$ & $1(2.6 \%)$ \\
\hline -SCA: & $1(2.6 \%)$ \\
\hline Anesthetic modality & \\
\hline -General anaesthesia & $19(59.4 \%)$ \\
\hline -Conscious sedation & $13(40.6 \%)$ \\
\hline IVT & $18(56.3 \%)$ \\
\hline
\end{tabular}




\begin{tabular}{|c|c|c|}
\hline Average delays: minutes $( \pm$ S.D $)$ & \multirow[b]{2}{*}{$\begin{array}{l}235.5( \pm 113.8) \\
67.7( \pm 33.4) \\
85.5( \pm-38)\end{array}$} & \\
\hline $\begin{array}{l}\text {-Symptoms' onset to arterial puncture } \\
\text {-Arterial puncture to successful recanalization } \\
\text {-Procedure lasting }\end{array}$ & & \\
\hline Median aspiration attempts: (IQR) & $2(1-5)$ & \\
\hline $\begin{array}{l}\text { TICI score: } \\
\text {-0: No perfusion } \\
\text {-1: Antegrade flow past the initial obstruction with } \\
\text { minimal perfusion } \\
\text {-2a: Partial reperfusion ( }<50 \% \text { of the occluded territory) } \\
\text {-2b: Partial reperfusion ( }>50 \% \text { of the occluded territory) } \\
\text {-3: Full reperfusion }\end{array}$ & $\begin{array}{l}\text { After ADAPT alone } \\
1(2.7 \%) \\
5(13.5 \%) \\
9(24.4 \%) \\
6(16.2 \%) \\
16(43.2 \%)\end{array}$ & $\begin{array}{l}\text { Final } \\
1(2.6 \%) \\
1(2.6 \%) \\
7(18.5 \%) \\
9(23.7 \%) \\
20(52.6 \%)\end{array}$ \\
\hline $\begin{array}{l}\text { Complications } \\
\text {-Mortality at one month: } \\
\text {-SICH: } \\
\text {-3MAX-related: }\end{array}$ & $\begin{array}{l}4(12.5 \%) \\
3(9.4 \%) \\
3(9.4 \%): \\
\bullet \quad 2 \text { ENTs } \\
\bullet \quad 1 \text { vascular perf }\end{array}$ & \\
\hline
\end{tabular}

383 S.D: Standard Deviation; IVT: Intravenous Thrombolysis; IQR: Interquartile Range; TICI: Thrombolysis In 384 Cerebral Infarction; Symptomatic Intracranial Hemorrhages; A3: Callosal segment of the anterior cerebral artery; M2: Insular segment of middle cerebral artery (MCA); M3: Opercular segment of the MCA; P1: Precommunicating segment of the posterior cerebral artery (PCA); P2: Ambient segment of the PCA; P3: Tectal segment of the PCA; SCA: superior cerebellar artery; ENT: Embolus to New Territory. 


\begin{tabular}{|c|c|c|c|c|c|c|c|}
\hline Series & Population & $\begin{array}{c}\text { Pre-treatment } \\
\text { NIHSS }\end{array}$ & Device/Technique & $\begin{array}{c}\text { TICI } 2 \mathrm{~b} / 3 \\
\text { reperfusion rate }\end{array}$ & $\begin{array}{l}\text { Embolization } \\
\text { to new territory }\end{array}$ & $\begin{array}{c}\text { Procedure-related } \\
\text { death }\end{array}$ & $\begin{array}{l}0-2 \mathrm{mRS} \text { at } \\
\text { follow-up }\end{array}$ \\
\hline $\begin{array}{l}\text { Pfaff J. et al. } \\
(2015)[21]\end{array}$ & $\begin{array}{l}30 \text { occlusions of } \\
\text { the distal ACA }\end{array}$ & 18 & Stent retriever & $88 \%$ & $0 \%$ & $0 \%$ & $36.2 \%$ at 90 days \\
\hline $\begin{array}{c}\text { Dorn et al. (2015) } \\
{[20]}\end{array}$ & 15 M2 occlusions & 13.73 & Stent retriever & $93.3 \%$ & $0 \%$ & $0 \%$ & $60 \%$ at 3 months \\
\hline $\begin{array}{l}\text { Kurre W. et al. } \\
\text { (2016) [22] }\end{array}$ & $\begin{array}{c}76 \text { patients for } 90 \\
\text { occlusions }\end{array}$ & 14 & $\begin{array}{l}\text { Stent retriever } \\
\text { (pREset LITE) }\end{array}$ & $70.0 \%$ & $13.3 \%$ & $0 \%$ & $\sim 34 \%$ at 90 days \\
\hline $\begin{array}{l}\text { Coutinho JM. et } \\
\text { al. (2016) [23] }\end{array}$ & $50 \mathrm{M} 2$ occlusions & 13 & $\begin{array}{l}\text { MERCI, Stent } \\
\text { retriever }\end{array}$ & $85 \%$ & NA & NA & $60 \%$ at 90 days \\
\hline $\begin{array}{l}\text { Kim DW. et al. } \\
\text { (2016) }[24]\end{array}$ & $41 \mathrm{M} 2$ occlusions & 13 & $\begin{array}{l}\text { FAST }^{*}, \text { Stent } \\
\text { retriever }\end{array}$ & $78 \%$ & $0 \%$ & NA & $\begin{array}{c}80.5 \% \text { at } 3 \\
\text { months }\end{array}$ \\
\hline $\begin{array}{l}\text { Park JS. et al. } \\
\text { (2016) [25] }\end{array}$ & $32 \mathrm{M} 2$ occlusions & 10.9 & $\begin{array}{c}\text { Manual aspiration } \\
\text { (4MAX) }\end{array}$ & $84 \%$ & $0 \%$ & $0 \%$ & $78 \%$ at 3 months \\
\hline $\begin{array}{l}\text { Vargas J. et al. } \\
(2016)[10]\end{array}$ & 35 patients & 14 & $\begin{array}{c}\text { ADAPT } \\
(5 / 4 / 3 \mathrm{MAX})\end{array}$ & $77.1 \%$ & NA & $0 \%$ & $59.4 \%$ at 90 days \\
\hline Presented study & $\begin{array}{l}32 \text { patients for } 37 \\
\text { occlusions }\end{array}$ & 14 & ADAPT (3MAX) & $\begin{array}{c}\text { 3MAX alone: } 59.5 \% \\
\text { Overall: } 76.3 \%\end{array}$ & $6.3 \%$ & $3.1 \%$ & $\begin{array}{c}45.5 \% \text { at } 3 \\
\text { months }\end{array}$ \\
\hline
\end{tabular}


